\title{
Stress Electrocardiography
}

National Cancer Institute

\section{Source}

National Cancer Institute. Stress Electrocardiography. NCI Thesaurus. Code C80406.

A recording of cardiac electrical activity during stress or exercise. 